ARTICLE

\title{
Invasive activity of Galega orientalis Lam. in the presence of deposits in the southwestern part of the Central Russian Upland
}

\author{
Vladimir Chernyavskikh ${ }^{\mathrm{a}}$, Elena Dumacheva ${ }^{\mathrm{a}}$ and Fedor Lisetskii
}

aDepartment of Biology, Belgorod State National Research University, Belgorod, Russian Federation;

'Institute of Earth Sciences, Belgorod State National Research University, Belgorod, Russian Federation

\begin{abstract}
The paper presents research into invasive activity of a model population of Galega orientalis, formed on deposits in the Central Russian Upland. It was found that the studied population did not show high invasiveness. Individual individuals that survived in competition with native grasses had a number of properties in the rhizosphere that distinguished them from the entire original population. It was found that the forms of $\mathrm{G}$. orientalis that survive when grown together in competition with cereals can pose an invasive threat. At the same time, individuals of $G$. orientalis may have different environmental functions from the rest of the population, manifested in the zone of the rhizosphere. It is suggested that the offspring of these forms can be competitive with native species, even in the arid South of Russia.
\end{abstract}

\section{KEYWORDS}

Invasiveness; agrocenoses; morphometric parameters; rhizosphere; soil

\section{Introduction}

Active dispersal of alien plant species can cause serious environmental changes in the flora of various regions, reduce biological diversity, and threaten sustainable development [1,2]. One of the most important causes for effective invasions is the appearance of large fallow land areas formed after the suspension of agricultural production. As soon as ploughing is stopped, any change in vegetation caused by relationships between plants [3] or spontaneous changes in their life environment brought [4,5] about by them refers to autogenic succession. Invasive species can disperse rapidly with a wide ecological amplitude and high fecundity [6,7]. The expansion of groups of invasive species in various types of natural and anthropogenic habitats has become a characteristic problem in the territory of the south-west of the Middle Central Russian Highland (Russia, the Belgorod region) [8-10].

In recent years, the Galega orientalis Lam. species, which is widely used in agriculture, has been increasingly considered as potentially invasive $[11,12]$. In the Black Book of the Central Russian Flora, G. orientalis is included in a list of plants tending to expand their range [13].

CONTACT Fedor Lisetskii liset@bsu.edu.ru $\mathbf{Q}$ Institute of Earth Sciences, Belgorod State National Research University, Belgorod 308015, Russian Federation 
In the conditions of the South-Western part of the Central Russian Upland, the distribution of $G$. orientalis is typical for agrophytocenoses. Yet to understand the trends of $G$. orientalis dispersal it is not enough just to have studies of invasive activity. It has been established that the population density tends to decrease, when being shaded by forest canopy and introduced into edge ecotones. It is suggested that this lightdemanding species has the potential to expand its secondary range only in open landscapes $[14,15]$.

In this regard, for the forest-steppe zone with natural steppe plant communities dominating on gully slopes, it is of great importance to analyse the interaction between alien species and herbaceous vegetation in the process of successions.

The aim of the studies conducted is to examine environmental characteristics and invasive activity of the $G$. orientalis Lam. model populations in the presence of longterm fallow in the forest-steppe zone of the southwestern part of the Central Russian Upland.

\section{Material and methods}

The study area is the southwestern part of the Central Russian Upland. The territory is characterised by erosional landforms and prevailing slope-type terrain. The climate is moderately continental. The average amount of solar radiation is approximately 4000 $\mathrm{MJ} / \mathrm{m}^{2}$ with the sunshine duration of about 1800 hours. The average annual temperature is $6.3^{\circ} \mathrm{C}$; the frost-free period is 157 days; the average annual precipitation is $530-$ $550 \mathrm{~mm}$, and it can range from 300 to $750-800 \mathrm{~mm}$ in occasional years. The soil cover is mainly represented by typical and leached Chernozems. The probability of dry years is about $50 \%$ [16].

The studies were conducted in 1999-2017 on permanent pilot sites. The studies were concerned with an artificial population of $G$. orientalis (Gale selection variety) developed in 1998 by seeding on model plots adjacent to the gully. The area of one model site is $12 \mathrm{~m}^{2}$; the replication is four-time. Coordinates: $1.50^{\circ} 30^{\prime} 23.5^{\prime \prime} \mathrm{N} 36^{\circ}$ $26^{\prime} 31.4^{\prime \prime} \mathrm{E}, 2.50^{\circ} 30^{\prime} 23.0^{\prime \prime} \mathrm{N} 36^{\circ} 26^{\prime} 32.4^{\prime \prime} \mathrm{E}, 3.50^{\circ} 30^{\prime} 22.8^{\prime \prime} \mathrm{N} 36^{\circ} 26^{\prime} 33.4^{\prime \prime} \mathrm{E}, 4.50^{\circ} 30^{\prime} 22.7^{\prime \prime} \mathrm{N}$ $36^{\circ} 26^{\prime} 34.2^{\prime \prime} \mathrm{E}$. The total area of the plot is 3 ha; the slope is about $5^{\circ}$ with Northern exposure. The soil is slightly washed-off clay loam and leached Chernozem. Until 2004, this plot was used for scientific research into various types of perennial grasses and their mixtures intended for grassing-down of eroded arable land. Since 2004, no agricultural activities have been conducted on the plot, and it is currently used as fallow land.

To study the number of stems (stems $/ \mathrm{m}^{2}$ ), aboveground phytomass during the fruiting stage ( $\mathrm{g} \mathrm{m}^{-2}$ absolutely dry matter), and seed growing potential (seeds $/ \mathrm{m}^{2}$ ), sample plots of $1 \mathrm{~m}^{2}$ were established. To assess main morphometric parameters, different stems were used. Stem weight (absolutely dry matter (a.d.m.)); height (cm); number of beans (beans/1 stem); and number of seeds (seeds/1 stem) were calculated. A reproductive effort was calculated as the ratio of seed mass to absolutely dry weight of the aboveground part of the plants (\%).

To obtain comparable results, all studies were conducted according to the common plan both in 1999-2004 and in 2016-2017. The overall projective cover (\%), average grass stand height $(\mathrm{cm})$, and aboveground phytomass $\left(\mathrm{g} \mathrm{m}^{-2}\right.$ absolutely dry matter) were 
evaluated. The species composition and abundance of plant species on the model plots were studied using the Braun-Blanquet method [17]. The names of species are given according to the summary of S.K. Cherepanov [18].

Rhizospheric (RS) and off-rhizospheric (ORS) soil were separated by mechanical shaking of plant roots for 5 minutes [19]. Chemical analysis of rhizospheric and offrhizospheric soil was performed by standard methods: determination of $\mathrm{K}_{2} \mathrm{O}$ and $\mathrm{P}_{2} \mathrm{O}_{5}$ mobile forms by Chirikov method as modified by CINAO (GOST 26204-91); N-NO 3 by ionometric express-method (OST 46-49-76); definition of $\mathrm{pH}_{\mathrm{KCl}}$ : potentiometrically; nitrification capacity $(\mathrm{NC})$ : according to the guidelines; $\mathrm{N}_{\text {total }}$ : photoelectrocalorimetrically (GOST 26107-84); and $\mathrm{S}_{\text {total }}$ : by pyrophosphate method [20]. The soil moisture in a metre-deep layer was determined by the thermostat-weight method twice during the season. We drilled on each plot two wells for soil sampling in the spring (before the beginning of the growing season) and two wells in the summer (during the seed formation period). Thus, eight samples each in spring and summer $(n=16)$ were selected and studied.

The soil density was studied by the cutting ring method. Samples were taken in layers every $10 \mathrm{~cm}$. Productive moisture stocks were calculated using the obtained data.

The obtained data were processed by standard statistical methods [21] using the Microsoft Excel software.

\section{Results and its discussion}

At the first stage, chemical agents provided the $G$. orientalis artificial population with favourable conditions for growth and development as compared to native species because of soil cultivation and related vegetation in-crop destruction. Moreover, taking into account the high invasive activity of this species $[2,14,22,23]$ indicated by numerous authors, it could be expected that it would quickly take over the territory of the entire plot after the suspension of its use in agricultural production.

The results of our research have shown that during its maximum development in the sixth year of its life, G. orientalis formed a monodominant community with a dense grass stand, which included tall and massive generative stems. Its aboveground phytomass reached more than $900 \mathrm{~g} \mathrm{~m}^{-2}$ of absolutely dry matter (a.d.m.), thus preventing other plant species from taking roots (Table 1).

There was no further expansion of the area occupied by the population. In all the model plots, it was consistently within its original boundaries. When the soil cultivation was suspended and fallow soil formed, the plots began to be populated with cereals, most intensively, with Arrhenatherum elatius, Elytrigia intermedia, Elytrigia repens, by transferring seeds from the natural plant communities of adjacent gullies and pilot crops.

The assessment of aboveground phytomass elements, which was carried out after 12 years of the $G$. orientalis population growth at one site, has shown that there was a significant decrease in the number of stems by $98.1-98.2 \%$, of which weight - by $83.8-$ $88.5 \%$, by height - by $76.2-78.3 \%$, and the amount of aboveground phytomass - by $99.6-$ 99.7\%. These data indicate a depressive state of the population.

A similar pattern was observed when the reproductive parameters were studied (Table 2). 
Table 1. The dynamics of the formation of aerial productivity elements of the artificial population of G. orientalis.

\begin{tabular}{|c|c|c|c|c|c|}
\hline Index & Year & $\mathrm{n}$ & $\mathrm{M} \pm \mathrm{m}^{*} \mathrm{t}_{\mathrm{st}} 0.01$ & 6 & $C_{w}, \%$ \\
\hline \multirow[t]{6}{*}{ The number of generative stems, pcs $\mathrm{m}^{-2}$} & 1999 & 16 & $3.2 \pm 1.1$ & 1.5 & 48.4 \\
\hline & 2000 & 16 & $20.9 \pm 2.1$ & 2.8 & 13.6 \\
\hline & 2002 & 16 & $92.2 \pm 4.4$ & 5.9 & 6.4 \\
\hline & 2004 & 16 & $121.8 \pm 4.1$ & 5.6 & 4.6 \\
\hline & 2016 & 9 & $2.2 \pm 1.2$ & 1.2 & 55.9 \\
\hline & 2017 & 9 & $2.1 \pm 1.6$ & 1.6 & 76.0 \\
\hline \multirow[t]{6}{*}{ The mass of one stem, $g$ a.d.m. } & 1999 & 100 & $1.4 \pm 0.1$ & 0.2 & 17.9 \\
\hline & 2000 & 100 & $2.8 \pm 0.2$ & 0.7 & 23.7 \\
\hline & 2002 & 100 & $6.2 \pm 0.4$ & 1.4 & 21.7 \\
\hline & 2004 & 100 & $10.5 \pm 0.6$ & 2.0 & 19.2 \\
\hline & 2016 & 30 & $1.2 \pm 0.5$ & 1.0 & 84.4 \\
\hline & 2017 & 30 & $1.7 \pm 0.5$ & 1.0 & 57.5 \\
\hline \multirow[t]{6}{*}{ Stem height, cm } & 1999 & 100 & $49.6 \pm 6.3$ & 7.8 & 15.7 \\
\hline & 2000 & 100 & $73.3 \pm 2.3$ & 11.4 & 15.5 \\
\hline & 2002 & 100 & $112.3 \pm 3.4$ & 7.4 & 6.6 \\
\hline & 2004 & 100 & $135.8 \pm 2.2$ & 7.0 & 5.1 \\
\hline & 2016 & 30 & $32.3 \pm 2.1$ & 13.4 & 32.0 \\
\hline & 2017 & 30 & $29.4 \pm 4.3$ & 7.9 & 42.0 \\
\hline \multirow[t]{6}{*}{ Elevated phytomass in the fruiting phase, $\mathrm{g} \mathrm{m}^{-2}$} & 1999 & 16 & $176.1 \pm 16.3$ & 22.9 & 13.0 \\
\hline & 2000 & 16 & $319.4 \pm 21.9$ & 29.7 & 9.3 \\
\hline & 2002 & 16 & $668.3 \pm 55.7$ & 75.5 & 11.3 \\
\hline & 2004 & 16 & $909.6 \pm 52.3$ & 70.9 & 7.8 \\
\hline & 2016 & 9 & $2.7 \pm 1.8$ & 1.8 & 68.3 \\
\hline & 2017 & 9 & $3.1 \pm 3.0$ & 3.0 & 97.7 \\
\hline
\end{tabular}

Table 2. Changes in the reproductive indicators of the artificial population of G. orientalis.

\begin{tabular}{lrrrrr}
\hline Index & Year & $\mathrm{n}$ & $\mathrm{M} \pm \mathrm{m}^{*} \mathrm{t}_{\text {st } 0.01}$ & \multicolumn{1}{c}{$\sigma$} & $\mathrm{CV} \%$ \\
\hline The number of beans on one stem, pcs. & 1999 & 100 & $9.0 \pm 1.4$ & 4.6 & 51.3 \\
& 2000 & 100 & $14.0 \pm 1.7$ & 5.6 & 39.7 \\
& 2002 & 100 & $34.0 \pm 1.1$ & 3.7 & 10.9 \\
& 2004 & 100 & $63.3 \pm 4.7$ & 16.0 & 25.3 \\
& 2016 & 30 & $2.5 \pm 1.0$ & 1.8 & 71.2 \\
& 2017 & 30 & $2.1 \pm 1.1$ & 2.0 & 93.8 \\
The number of seeds on one stem, pcs. & 1999 & 100 & $14.6 \pm 3.3$ & 11.3 & 77.4 \\
& 2000 & 100 & $27.4 \pm 4.2$ & 14.3 & 52.3 \\
& 2002 & 100 & $98.7 \pm 7.8$ & 26.3 & 26.7 \\
& 2004 & 100 & $188.7 \pm 10.9$ & 36.8 & 19.5 \\
& 2016 & 30 & $1.9 \pm 1.1$ & 2.1 & 112.2 \\
The value of seed productivity, pcs $/ \mathrm{m}^{2}$ & 2017 & 30 & $3.2 \pm 1.8$ & 3.3 & 104.0 \\
& 1999 & 16 & $58.2 \pm 47.3$ & 64.2 & 110.2 \\
& 2000 & 16 & $562.2 \pm 202.2$ & 274.2 & 48.8 \\
& 2002 & 16 & $9071.0 \pm 1770.9$ & 2401.2 & 26.5 \\
& 2004 & 16 & $22,888.4 \pm 2960.7$ & 4014.5 & 17.5 \\
& 2016 & 9 & $2.4 \pm 2.1$ & 2.5 & 102.4 \\
Reproductive effort, \% & 2017 & 9 & $10.1 \pm 12.3$ & 14.4 & 142.8 \\
& 1999 & 16 & $0.1 \pm 0.1$ & 0.1 & 114.4 \\
& 2000 & 16 & $0.6 \pm 0.3$ & 0.4 & 59.3 \\
& 2002 & 16 & $5.2 \pm 1.0$ & 1.3 & 24.6 \\
& 2004 & 16 & $7.7 \pm 1.0$ & 1.3 & 17.0 \\
& 2016 & 9 & $0.5 \pm 0.5$ & 0.6 & 128.9 \\
& 2017 & 9 & $0.7 \pm 0.7$ & 0.8 & 115.2 \\
\hline
\end{tabular}

Twelve years after the transfer of the land plot to the fallow stock, both the seed productivity and reproductive effort have decreased to minimum values in $G$. orientalis plants. A value variation degree has increased for all examined characteristics in relation to productive stems. If during the period of maximum population development, the seed 
productivity variation factor for a single stem was 26.7\%, in 2016-2017 this indicator increased up to $10 \%$. Table 3 shows the descriptions of plant communities, which have formed out of the $G$. orientalis individual species on the model plots over the past 12 years instead of mono-dominant ones.

It was established that the abundance of $G$. orientalis was minimal by the time of the descriptions. Mono-dominant cereal communities were formed because of the dominance of species, such as $A$. elatius and $E$. repens. Other types of cereals were reported to be introduced. The share of $G$. orientalis did not exceed $0.5 \%$ in the composition of phytomass of a highly productive cereal community. The results of the studies have shown that in the presence of a long-term fallow on leached Chernozem, the examined population of $G$. orientalis had neither high invasive activity nor high seed productivity to create a sufficient seed bank. Contrary to our assumptions, the G. orientalis species failed to form a stable, long-lived, and mono-dominant community and to displace local native species. Apparently, this is because G. orientalis is a Caucasian species, which is naturally dispersed in ecotopes with sufficient moisture: on mountain forest edges, in forest glades, along stream banks, etc. [24]. In the conditions of unstable and insufficient moisture in the Southern part of the Central Russian Upland, possible fallow invasion of G. orientalis can be limited by water-physical properties of Chernozem soils, which largely determine their water status [25].

Table 4 shows the results of analysis of the soil density dynamics and the closely related parameter on the available moisture content in various soil layer horizons.

The following was determined: firstly, a significant density rise in a $0-20 \mathrm{~cm}$ soil layer with increase in the fallow time; secondly, a decrease in total productive moisture stocks in a metre-deep soil layer, with the most significant decrease in a $50-100 \mathrm{~cm}$ layer.

In fact, vegetation growth and development occurred with a general lack of moisture. Under these conditions, the native species, especially cereals, were more competitive than the adventive moisture-loving $G$. orientalis species. A downward trend was identified for the G. orientalis share in the community, as the soil density increases ( $\mathrm{r}=-0.612 \pm 0.181$, $\mathrm{p}<0.05)$, the available moisture decreases in a $0-100 \mathrm{~cm}$ layer $(\mathrm{r}=-0.589 \pm 0.201, \mathrm{p}<0.05)$, and the moisture reduces in a $50-100 \mathrm{~cm}$ layer $(\mathrm{r}=-0.724 \pm 0.112, \mathrm{p}<0.05)$, which is confirmed by a negative moderate correlation. Along with this, a close positive relationship

Table 3. Characteristics of species with the greatest abundance in communities at model sites.

\begin{tabular}{lcccc}
\hline Description serial number & 1 & 2 & 3 & 4 \\
\hline Sites area, $\mathrm{m}^{2}$ & 12 & 12 & 12 & 12 \\
Projective cover, $\%$ & $95-100$ & $95-100$ & $95-100$ & $95-100$ \\
Length of stand, cm & 85 & 80 & 65 & 75 \\
Elevated phytomass, $\mathrm{g} \mathrm{m}^{-2}$ a.d.m. & $655 \pm 42^{*}$ & $640 \pm 30^{*}$ & $603 \pm 36^{*}$ & $564 \pm 34^{*}$ \\
Abundance of species & & & & \\
Galega orientalis & + & + & 5 & 5 \\
Arrhenatherum elatius & 4 & 4 & 1 & + \\
Elytrigia repens & 3 & 2 & + & + \\
Elytrigia intermedia & 1 & 1 & 2 & 2 \\
Poa angstifolia & 1 & 1 & - & - \\
Dactylis glomerata & + & 1 & + & + \\
Bromopsis inermis & 1 & & & \\
\hline
\end{tabular}

* $n=9$, significance level $p<0.01$. 
Table 4. Changes in productive moisture reserves in soil under an artificial population G. orientalis.

\begin{tabular}{|c|c|c|c|c|c|c|}
\hline Years & Warning & $\mathrm{H}, \mathrm{cm}$ & $n$ & $\mathrm{M} \pm \mathrm{m}^{*} \mathrm{t}_{\text {st }} 0.05$ & 6 & $C_{v r} \%$ \\
\hline \multirow[t]{2}{*}{ 1999-2002 } & $P_{d}{ }^{*}, g ~ c m^{-3}$ & $0-20$ & 16 & $1,15 \pm 0,06$ & 0,12 & 10,0 \\
\hline & & $20-50$ & 16 & $1,20 \pm 0,06$ & 0,11 & 9,2 \\
\hline \multirow[t]{2}{*}{$2016-2017$} & $P_{d}, g ~ c m^{-3}$ & $0-20$ & 16 & $1,35 \pm 0,05$ & 0,10 & 7,2 \\
\hline & & $20-50$ & 16 & $1,26 \pm 0,04$ & 0,08 & 6,3 \\
\hline \multirow[t]{4}{*}{1999} & $W^{* * *}, \mathrm{~m}^{3} \mathrm{ha}^{-1}$ & $0-20$ & 16 & $181 \pm 45$ & 85 & 47 \\
\hline & & $20-50$ & 16 & $265 \pm 57$ & 108 & 41 \\
\hline & & $50-100$ & 16 & $589 \pm 47$ & 89 & 15 \\
\hline & & $0-100$ & 16 & $1035 \pm 146$ & 274 & 26 \\
\hline \multirow[t]{4}{*}{2000} & W, $\mathrm{m}^{3} \mathrm{ha}^{-1}$ & $0-20$ & 16 & $182 \pm 50$ & 94 & 52 \\
\hline & & $20-50$ & 16 & $249 \pm 50$ & 94 & 38 \\
\hline & & $50-100$ & 16 & $607 \pm 61$ & 115 & 19 \\
\hline & & $0-100$ & 16 & $1037 \pm 15$ & 284 & 27 \\
\hline \multirow[t]{4}{*}{2002} & $W, \mathrm{~m}^{3} \mathrm{ha}^{-1}$ & $0-20$ & 16 & $193 \pm 51$ & 96 & 50 \\
\hline & & $20-50$ & 16 & $248 \pm 45$ & 85 & 34 \\
\hline & & $50-100$ & 16 & $584 \pm 51$ & 96 & 16 \\
\hline & & $0-100$ & 16 & $1025 \pm 140$ & 263 & 26 \\
\hline \multirow[t]{4}{*}{2004} & $\mathrm{~W}, \mathrm{~m}^{3} \mathrm{ha}^{-1}$ & $0-20$ & 16 & $232 \pm 24$ & 46 & 20 \\
\hline & & $20-50$ & 16 & $244 \pm 42$ & 78 & 32 \\
\hline & & $50-100$ & 16 & $549 \pm 67$ & 126 & 23 \\
\hline & & $0-100$ & 16 & $1025 \pm 13$ & 244 & 24 \\
\hline \multirow[t]{4}{*}{2016} & $\mathrm{~W}, \mathrm{~m}^{3} \mathrm{ha}^{-1}$ & $0-20$ & 16 & $163 \pm 44$ & 83 & 51 \\
\hline & & $20-50$ & 16 & $231 \pm 40$ & 76 & 33 \\
\hline & & $50-100$ & 16 & $342 \pm 31$ & 59 & 17 \\
\hline & & $0-100$ & 16 & $736 \pm 105$ & 197 & 27 \\
\hline \multirow[t]{4}{*}{2017} & W, $\mathrm{m}^{3} \mathrm{ha}^{-1}$ & $0-20$ & 16 & $171 \pm 57$ & 107 & 63 \\
\hline & & $20-50$ & 16 & $223 \pm 36$ & 68 & 31 \\
\hline & & $50-100$ & 16 & $318 \pm 31$ & 59 & 18 \\
\hline & & $0-100$ & 16 & $712 \pm 119$ & 223 & 31 \\
\hline
\end{tabular}

* $P_{\mathrm{d}}$ is absolutely dry soil density, $\mathrm{g} \mathrm{cm}^{-3} ; *$ is reserves of productive moisture, $\mathrm{m}^{3} \mathrm{ha}^{-1}$.

was shown between the increased cereal component share in the community and the soil density $(r=0.891 \pm 0.232, p<0.05)$ and the decreased content of available moisture both in the metre-deep layer $(\mathrm{r}=0.814 \pm 0.219, \mathrm{p}<0.05)$ and in the $50-100 \mathrm{~cm}$ horizon $(\mathrm{r}=0.831 \pm 0.174, \mathrm{p}<0.05)$. Thus, the higher the fallow age is, the more favourable the waterphysical soil properties become for native species as compared to the adventive $G$. orientalis species.

One of the main factors affecting the growth and development of plants is their sufficiency in nutrients. The specific invasive activity depends on mineral consumption efficiency, which is determined by underground environment formation processes in the rhizosphere, as well as by synthetic process activity in the roots and in the aerial part of plants [26].

Changes in soil chemical parameters in the rhizosphere and beyond the rhizosphere under the $G$. orientalis artificial population were assessed. The results have shown that the individual species, which dominated at the first stage of its life in 2000-2004, differed in the rhizospheric soil chemical composition from those which remained to be competitive with cereals by 2016-2017 (Table 5).

It has been established that in the soil under the individual species, which survived by 2016, the $\mathrm{pH}_{\mathrm{KCl}}$ value is alkaline-oriented in the rhizosphere zone $\left(\mathrm{pH}_{\mathrm{KCl}}=6.98 \pm 0.12\right)$ and significantly differs from $\mathrm{pH}_{\mathrm{KCl}}$ both beyond and within the root layer of soil under the original population with $\mathrm{pH}_{\mathrm{KCl}}$ being vice versa shifted towards acidification in comparison with the surrounding soil. 
Table 5. Changes in the chemical parameters of soil under an artificial population G. orientalis.

\begin{tabular}{|c|c|c|c|c|c|c|}
\hline Index & Years & Soill $^{*}$ & $\mathrm{n}$ & $M \pm m^{* * * * *} t_{5 t} 0.01$ & 6 & $C_{w} \%$ \\
\hline \multirow[t]{4}{*}{$\mathrm{pH}_{\mathrm{kCl}}$} & $2002-2004$ & ERS & 8 & $6.10 \pm 0.43$ & 0.35 & 5.7 \\
\hline & & $\mathrm{RS}$ & 8 & $5.91 \pm 0.41$ & 0.33 & 5.6 \\
\hline & 2016-2017 & ERS & 8 & $6.15 \pm 0.33$ & 0.27 & 4.3 \\
\hline & & RS & 8 & $6.98 \pm 0.12^{* * *}$ & 0.08 & 1.4 \\
\hline \multirow{4}{*}{$\mathrm{N}_{\text {tot }} \%$} & $2002-2004$ & ERS & 8 & $0.32 \pm 0.03$ & 0.03 & 8.4 \\
\hline & & RS & 8 & $0.36 \pm 0.05$ & 0.01 & 10.7 \\
\hline & $2016-2017$ & ERS & 8 & $0.41 \pm 0.02$ & 0.02 & 5.0 \\
\hline & & RS & 8 & $0.46 \pm 0.02^{* * *}$ & 0.02 & 3.9 \\
\hline \multirow[t]{4}{*}{$C_{\text {tot.. }} \%$} & 2002-2004 & ERS & 8 & $2.44 \pm 0.24$ & 0.19 & 8.0 \\
\hline & & RS & 8 & $2.63 \pm 0.37$ & 0.30 & 11.2 \\
\hline & $2016-2017$ & ERS & 8 & $2.89 \pm 0.35$ & 0.28 & 9.8 \\
\hline & & RS & 8 & $3.52 \pm 0.22^{*}$ & 0.18 & 5.1 \\
\hline \multirow[t]{4}{*}{$\mathrm{P}_{2} \mathrm{O}_{5}, \mathrm{mg} \mathrm{kg}^{-1}$} & $2002-2004$ & ERS & 8 & $186 . \pm 27.1$ & 21.9 & 11.8 \\
\hline & & RS & 8 & $230.2 \pm 29.0$ & 23.5 & 10.2 \\
\hline & 2016-2017 & ERS & 8 & $169.8 \pm 26.4$ & 21.4 & 12.6 \\
\hline & & RS & $5^{* * *}$ & $88.7 \pm 22.2^{* * *}$ & 11.0 & 10.1 \\
\hline \multirow[t]{4}{*}{$\mathrm{K}_{2} \mathrm{O}, \mathrm{mg} \mathrm{kg}^{-1}$} & $2002-2004$ & ERS & 8 & $112.1 \pm 22.7$ & 18.4 & 16.4 \\
\hline & & RS & 8 & $148.7 \pm 22.5$ & 18.1 & 12.2 \\
\hline & $2016-2018$ & ERS & 8 & $121.9 \pm 24.9$ & 20.1 & 16.5 \\
\hline & & RS & $5^{* *}$ & $97.0 \pm 14.6$ & 7.3 & 6.2 \\
\hline \multirow[t]{4}{*}{$\mathrm{N}-\mathrm{NO}_{3}, \mathrm{mg} \mathrm{kg}^{-1}$} & $2002-2004$ & ERS & 8 & $7.3 \pm 2.2$ & 1.8 & 24.2 \\
\hline & & RS & 8 & $9.3 \pm 1.0$ & 0.8 & 8.3 \\
\hline & $2016-2017$ & ERS & 8 & $7.0 \pm 0.8$ & 0.7 & 9.5 \\
\hline & & RS & 8 & $5.0 \pm 0.4^{* * *}$ & 0.4 & 7.2 \\
\hline \multirow[t]{4}{*}{$\mathrm{HC}, \mathrm{mg} \mathrm{kg}^{-1}$} & $2002-2004$ & ERS & 8 & $10.7 \pm 2.0$ & 1.6 & 14.9 \\
\hline & & RS & 8 & $13.3 \pm 1.1$ & 0.9 & 6.6 \\
\hline & $2016-2017$ & ERS & 8 & $11.2 \pm 1.1$ & 0.9 & 7.6 \\
\hline & & RS & 8 & $18.9 \pm 1.6^{* * *}$ & 1.3 & 6.8 \\
\hline
\end{tabular}

*Rhizospheric soil (RS) and Extra-Rhizospheric (ERS) soil; *** samples were taken that did not boil from 10\% hydrochloric acid (i.e. $\mathrm{pH}<7.0$ ) for analysis by the Chirikov method; ****** differences are significant at $\mathrm{p}<0.01 ; \mathrm{pH}_{\mathrm{KCl}}-\mathrm{pH}$ salt; $\mathrm{N}_{\text {tot. }}$ total nitrogen, \%; $\mathrm{C}_{\text {tot }}$ - group composition of humus carbon, \%; $\mathrm{P}_{2} \mathrm{O}_{5}$ - active forms of phosphorus, $\mathrm{mg} \mathrm{kg}^{-1} ; \mathrm{K}_{2} \mathrm{O}-$ active forms of potassium, $\mathrm{mg} \mathrm{kg}^{-1} ; \mathrm{N}-\mathrm{NO}_{3}$ - nitrate nitrogen, $\mathrm{mg} \mathrm{kg}^{-1} ; \mathrm{HC}$ - nitrification capacity of the soil, $\mathrm{mg} \mathrm{kg}^{-1}$.

The study of soils in places where viable individuals of G. orientalis survived by 2017 showed that the content of available phosphorus in the rhizosphere was significantly lower than in the soil outside the rhizosphere. In addition, the rhizosphere accumulated more carbon and total nitrogen, significantly less nitrate nitrogen, and it had a higher nitrification capacity.

The population eliminated the G. orientalis individual species with rhizosphere, which demonstrated continuing medium acidification alongside an increased content of available forms of phosphorus, potassium, and nitrate nitrogen. They appeared to be less long-standing than native cereals and apparently less competitive. It seems that this process can be considered as common to many types of perennial legumes growing in competition with cereals.

We found a similar trend for Medicago varia Mart., Lotus corniculatus L. and Medicago falcata L. species in our previous studies of changes in the rhizosphere chemical composition as compared to off-rhizospheric soil. Longer-lived and more competitive individual species were reported to have soil alkalisation and decreased amount of available forms of phosphorus and potassium in the rhizosphere. The individual species, which acidified the rhizospheric soil, were younger and less competitive than cereals. This was mostly observed in the $M$. varia species, which is an invasive plant in the region. The content of available nutrients was increased in the rhizosphere because of growing media acidification by root secretions from the original population's 
individual species in the first years of their life. This, in turn, contributed both to the penetration of cereal root systems into their rhizosphere and to the start of the process of competitive exclusion of unstable forms. The survival of populations was associated with the presence of individual species with rhizospheric $\mathrm{pH}_{\mathrm{KCl}}$ being shifted towards medium alkalisation, which made it less favourable for the penetration of cereal root systems $[27,28]$.

Thus, we have found that unstable individual species are competitively excluded through changes in rhizospheric soil conditions. For practical purposes, the method of competitive form evaluation was earlier tried out and tested by us in the course of growing artificial populations for effective isolation of $M$. varia individual species with a stress-tolerant life strategy. It has also been established that the ability to alkalise medium in rhizospheric soil was inherited in M. varia offspring [29].

\section{Conclusion}

The invasive $G$. orientalis artificial population with long-term fallow in the leached Chernozem under the conditions of the southwestern part of the Central Russian Upland has shown not expanded its area after the suspension of arable cultivation. After 17 years, the population was in a depressed state; it had 2.1-2.2 generative shoots per $\mathrm{m}^{2}$, a height of $29.4-32.3 \mathrm{~cm}$, and a mass of $1.2-1.7 \mathrm{~g} \mathrm{~m}^{-2}$. The surviving individual species formed at maximum 2.1-2.5 beans on one stem. After 12 years of being in a fallow land, the reproductive effort decreased from $5.2 \%$ to $7.7 \%$ during the period of maximum population development, when it was cultivated as a crop, down to $0.5-0.7 \%$. Over these years, the mono-dominant community has become a cereal one with a $G$. orientalis share of no more than $0.5 \%$.

Thus, within the long-term fallow, the studied G. orientalis population showed little invasive activity. Its range did not expand. There was no Galega orientalis fallow ramping, although this had been anticipated. A mono-dominant community did not form. The local native species were not displaced.

It was found the fallow areas formed the conditions for water availability, soil density, and chemical parameters of soil fertility, which prevented active competition of G. orientalis with cereals. During the study period, the artificial population did not have sufficient invasive potential and posed no threat to native communities in either seed bank formation, or vegetative reproduction activity, or allelopathic impact.

There is, however, a risk that invasive danger may come from the G. orientalis forms, which survive in the process of natural selection when co-growing in competition with cereals. It has been found that some G. orientalis individual species may have mediumforming functions, which are manifested within the rhizosphere zone and differ from the rest of the population. Such forms are preserved during long-term growth as part of cereal and legume grass stands, in the presence of arid conditions, when most individual species of the population are eliminated. They are easily ordinated by $\mathrm{pH}_{\mathrm{KCl}}$ rhizospheric shifting towards alkalisation and reduced level of available phosphorus in the rhizosphere as compared to the surrounding substrate. The offspring of these forms can compete, under certain conditions, with native species, even in the arid southern part of Russia. It is therefore advisable to monitor the populations of 
G. orientalis in the plots dominated by cereal grass stands and in areas with unstable and insufficient moisture.

\section{Disclosure statement}

No potential conflict of interest was reported by the author(s).

\section{ORCID}

Fedor Lisetskii (D) http://orcid.org/0000-0001-9019-4387

\section{References}

[1] Borisova, E., 2006, Floristic contamination of suburban forests near the city of Ivanovo. Russian Journal of Ecology 37(3), 152-155. doi:10.1134/\$1067413606030027

[2] Bromfield, E., Cloutier, S., Robidas, C., Thu, V.T.T., and Darbyshire, S., 2019, Invasive Galega officinalis (Goat's rue) plants in Canada form a symbiotic association with strains of Neorhizobium galegae sv. officinalis originating from the old world invasive plant species Galega orientalis. Ecology and Evolution 9(12), 699-7004.

[3] Lisetskii, F., 1998, Autogenic succession of steppe vegetation in postantique landscapes. Russian Journal of Ecology 29(4), 217-219.

[4] Lisetskii, F., Sudnik-Wojcikowska, B., and Moysiyenko, I., 2016, Flora differentiation among local ecotopes in the transzonal study of forest-steppe and steppe mounds. Biology Bulletin 43(2), 169-176. doi:10.1134/S1062359016010106

[5] Lisetskii, F. and Pichura, V., 2016, Steppe ecosystem functioning of East-European Plain under age-long climatic change influence. Indian Journal of Science and Technology 9(18), 1-9. doi:10.17485/ijst/2016/v9i18/93780

[6] Borisova, E., 2010, The special features of the invasive plant species spread throughout the Upper Volga region. Russian Journal of Biological Invasions 4, 2-9.

[7] Abramova, L., 2014, New data on biological invasions of alien species in the Republic of Bashkortostan. Bulletin of the Academy of Sciences of the Republic of Bashkortostan 19(4), $16-27$.

[8] Lisetskii, F., Tokhtar, V., Ostapko, V., Prykhodko, S., and Petrunova, T., 2016, Regularities and features of differentiation and anthropogenic transformation of steppe vegetation. In: M. Nguyen Ed. Terrestrial Biomes: Geographic Distribution, Biodiversity and Environmental Threats (New York: Nova Science Publishers, Inc.), pp. 103-125.

[9] Tokhtar, V., 2018, Advanced approaches to the visualization of data characterizing distribution features of alien plant species. Russian Journal of Biological Invasions 9(3), 263-269. doi:10.1134/S2075111718030153

[10] Kurskoy, A. and Tokhtar, V., 2019, Analysis of the peculiarities of the expansion of invasive plant species in the south-west of the middle Russian highland (Russia, the Belgorod region). EurAsian Journal of BioSciences 13(2), 1013-1016.

[11] Abramova, L., 2012, Expansion of invasive alien plant species in the republic of Bashkortostan, the Southern Urals: Analysis of causes and ecological consequences. Russian Journal of Ecology 43(5), 352-357. doi:10.1134/S1067413612050037

[12] Kondratiev, M. and Larikova, Y., 2018, The role of allelopathy in invasion of plant species (review). Bulletin of the Timiryazev Agricultural Academy 2, 48-61.

[13] Vinogradova, Y., Mayorov, S., and Khorun, L., 2010, The Black Book of Flora of Central Russia: Alien Plant Species in the Ecosystems of Central Russia (Moscow: GEOS). 
[14] Tkacheva, E., Vinogradova, Y., and Pavlova, I., 2011, Variability of morphometric features of Galega orientalis Lam. in some populations of the natural and secondary area. Russian Journal of Biological Invasions 3, 41-48.

[15] Tokhtar, V. and Kurskoy, A., 2019, Invasive Plants of the Southwest of the Central Russian Upland (Belgorod: Belgorod Publishing House Belgorod State University).

[16] Solovichenko, V., 2005, Fertility and Rational Use of Soils of the Belgorod Region (Belgorod: "Otchii krai").

[17] Mirkin, B. and Naumova, L., 1998, The Science of Vegetation: History and Current Status of Basic Concepts (Ufa: Gilem).

[18] Cherepanov, S., 1995, Vascular Plants of Russia and Neighboring States (Within the Former USSR) (St. Petersburg: Peace and Family).

[19] Zvyagintsev, D.G. (eds), 1991, Methods of Soil Microbiology and Biochemistry (Moscow: Publishing House of Moscow State University).

[20] Kononova, M. and Belchikova, N., 1961, Accelerated methods of determining the composition of humus of mineral soils. Soil Science 10, 75-87.

[21] Lakin, G.F., 1990, Biometrics (Moscow: Higher School publishing house).

[22] Vinogradova, Y.K., Kuklina, A.G., and Tkacheva, E.V., 2014, Invasive Species of Plants of the Legume Family (Lupine, Galega, Robinia, Amorpha, Caragana) (Moscow: ABF).

[23] Ebel, A.L., Kupriyanov, A.N., Strelnikova, T.O., Ankipovich, E.S., Antipova, E.M., Antipova, S.V., Buko, T.E., Verkhozina, A.V., Doronkin, V.M., Efremov, A.N., Zykova, E. Y., Kirina, A.O., Kovrigina, L.N., Lamanova, T.G., Mikhailova, S.I., Nozhinkov, A.E., Plikina, N.V., Silantieva, M.M., Stepanov, N.V., Tarasova, I.V., et al., 2016, The Black Book of Siberian Flora (Novosibirsk: Geo).

[24] Osterman, J.L., Chizhevskaja, E.P., Andronov, E.E., Fewer, D.P., Terefework, Z., Roumiantseva, M.L., Onichtchouk, O.P., Dresler-Nurmi, A., Simarov, B.V., Dzyubenko, N.I., and Lindström, K., 2011, Galega orientalis is more diverse than Galega officinalis in Caucasus-whole-genome AFLP analysis and phylogenetics of symbiosis-related genes. Molecular Ecology 20(22), 4808-4821. doi:10.1111/j.1365-294X.2011.05291.x

[25] Lisetskii, F., 2008, Agrogenic transformation of soils in the dry steppe zone under the impact of antique and recent land management practices. Eurasian Soil Science 41(8), 805-817. doi:10.1134/S1064229308080024

[26] Degtyar', O. and Chernyavskikh, V., 2006, The environment-forming role of endemic species in calciphilous communities of the southern Central Russian Upland. Russian Journal of Ecology 37(2), 143-145. doi:10.1134/S1067413606020135

[27] Dumacheva, E. and Chernyavskikh, V., 2012, Soil-rhizospheric interactions of some Fabaceae species during cultivation in culture on carbonate soils. Fundamental Studies 9 (2), 351-355.

[28] Dumacheva, E. and Chernyavskikh, V., 2016, Rhizospheric index as an indicator of the competitiveness of legumes in mixed crops on carbonate soils. International Scientific Ecological Conference, Krasnodar: Kuban State Agrarian University, 29-30 March.

[29] Dumacheva, E. and Cherniavskikh, V., 2014, The influence of method of hybrid alfalfa (Medicago varia mart.) cultivation on seed productivity of the first generation posterity on calcareous soils of the Central Chernozem region. Feed Production 2, 23-25. 